\title{
Assessment of natural variations in letter formations incorporating master pattern of handwriting
}

\author{
SHRUTI GUPTA \\ Amity Institute of Forensic Science, Amity University, Noida, India \\ RAKESH K. GARG \\ Department of Forensic Science, Punjabi University, Patiala, India. \\ SURINDER NATH \\ Department of Anthropology, Delhi University, New Delhi, India
}

\section{Introduction}

In the present scenario in document problems the question of "Natural Variations" is yet another important element that must be considered in the right perspective though none significant research has been reported in this area of specialization. The extent of variation differs among writers and, consequently, natural variation forms an important element in the identification of handwriting. In some cases, variation is slight and occurs only in minor details of the writing; in other instances, the formation of letters and words will vary widely about a master pattern (Kelly and Lindblom, 2006). An individual's handwriting is made up of a complexity of habitual patterns that are repeated within a typical range of variation around the model patterns. Regardless of the class of problems, variation is ever present and must be accurately evaluated. It is as much as a basic part of the identification as each identifying characteristic itself (Hilton, 
1982). The range of variations in writings of different dates or documents or instruments, appropriately called asynchronous writings, tends to be somewhat greater than that of synchronous (i.e., same date, place, and time) executions (Huber and Headrick, 1999).

Handwriting is made up of countless habitual patterns. Individuals learn to write differently due to the differences in the shape and size of their fingers, hands, and arms. The muscle coordination of these and perceptions of how an individual sense form helps each one to develop one's own Master Pattern of writing. Once an individual develops the master pattern, it cannot be eliminated. Handwriting may be characterized, not only in the form of its master pattern but also by the nature and extent of the variations around the master pattern exhibited by each individual letter design. The range of writing can also be named as the master pattern of the writer, includes all the characteristics, patterns, and idiosyncrasies that a writer uses when engaged in the act of writing. The position of the dots, crossing-strokes and placing of punctuation marks are highly characteristic in any handwriting. Every person places these marks according to his or her own individual habits and style. For instance, the comma may be either big or small; the position of the dots may be exactly over the stems of ' $\mathrm{i}$ ' or they may be placed towards the left or right. Similarly, the crossings of ' $t$ ' may be to the left of the stem or to the right, without touching the stem or it may cross the stem or main body.

Handwriting identification is a comparative study requiring authenticated specimens of known handwriting from the individual(s) concerned. These are closely compared to the handwriting characteristics exhibited by the questioned writing in order to determine authorship. Like must be compared to like: printing to printing and cursive to cursive, with comparable letters, letter combinations, words, and numerals (Huber \& Headrick, 1999).

Scientists have invented software's signatures verifications as McCabe et al.(2008) have considered that the most natural method of authenticating a person's identity is (compared to other biometric and cryptographic forms of authentication) the learning process inherent in Neural Networks (NN) that can be applied to the process of verifying handwritten signatures that are electronically captured via a stylus. The various static (e.g., height, slant, etc.) and dynamic (e.g., velocity, pen tip pressure, etc.) signature features are extracted and used to train the NN. 
According to them the resulting system performs reasonably well with an overall error rate of $3.3 \%$ being reported for the best case. Sarangi et al. (2012) designed a recognition systems for handwritten character applications that is a robust technique capable of dealing with natural variations in handwritten characters. In their research the performance of Hopfield neural network (HNN) model in recognizing the handwritten Oriya (an Indian language) digits is addressed. But none has initiated to extract out the letters that are prone to variations with due course of time and age, that could be unreliable for reaching to a conclusion in identifying one's handwriting whether it is genuine ot not. The objective to undertake this investigation is to trace out these letters (English alphabets) incorporating the concept of master pattern to it.

\section{Methodology}

A total number of 540 (60 samples from each age group- 30 samples each from males and females, has been collected from 9 different age groups i.e. 20 to 25 years, 25 to 30 years, 30 to 35 years, 35 to 40 years, 40 to 45 years, 45 to 50 years, 50 to 55 years, 55 to 60 years and 60 above. The exclusion method for continuous data classification has been adopted to classify above said age groups. (Gupta, 1996; Gupta, 2011).

The samples were collected from the individuals on A-4 sized plain paper sheet, two handwriting samples in present handwriting with content (a small paragraph consisting 4-8 lines) in English which was the same as the previous written script which is also taken as a sample for comparative study. In total 3 handwriting samples - two in present handwriting (with a gap of 5-10 minutes between the two handwritings) and one old or past handwriting sample collected from each individual (gap ranged from 2-33 years between present and old handwritings). In another A-4 sized paper, handwriting sample of capital letters $(\mathrm{A}-\mathrm{Z})$, small letters $(\mathrm{a}-\mathrm{z})$ which was supposed to show significant variations as well as digits (0-9) were taken. The samples were collected with '045 Reynolds fine carbure' ball point pen only. All samples from each age group were collected along with their personal details and signatures indicating their consent for handwriting sample. The collected samples were analyzed by Magnifying glass. 
The curious physical twist in the formations of characters i.e. Letter Formation has been studied in Past, Present - I and Present - II handwritings collected for present research from:

1) Crossing of alphabet ' $t$ ', lower loop of ' $\mathbf{y}$ ', ' $\mathbf{g}$ ', ' $\mathbf{f}$ '; upper loop of 'h', 'l', 'f', 'b', 'd' and dotting of alphabet 'i' etc.

2) Variation in most commonly used words like: is, but, are, and, for, will, to, at etc.

3) Connecting strokes between the letters of words.

4) Formation of alphabets.

5) The position of initial and terminal strokes.

6) Comma, inverted comma and full stop, and numerical figure formation.

\section{Results}

The range of writing, also called the master pattern of the writer, includes all the characteristics, patterns, and idiosyncrasies that a writer uses when engaged in the act of writing. For the purpose of analysis of the handwriting samples, the master of the pattern of individuals has been traced out along with taking in account different styles of writing adopted by the same individual in producing a single letter, and if, formation of letters were diverging from this range of writing i.e. master pattern that means variations have been prevailed. To avoid including accidental features which could be outside the range of writing, the same letter has been examined in Present - I and Present - II handwriting samples. The letters indicating variations or divergence from their regular range of writing in due course of time have been carefully observed on comparison between Past, Present - I and Present - II handwritings samples of same individual as shown in Table - 1 . In sample 1 and 2 for ' $A$ ', there is complete variation in the initial stroke, style of writing (letter written in different manner), appearance and formation of letter (over all formation of initial, middle and terminal stroke). In sample 3 for ' $a$ ', variation has been found in commencement of stroke, appearance and formation of letter. In sample 4 for 'B', variation has been observed style of writing, appearance and formation of letter. In sample 5 and 7 for ' $b$ ', variation in the 
formation of terminal stroke are present though similarity is observed in initial stroke of the letter. In sample 6 for ' $b$ ', complete variation has been found in style of writing, appearance and formation of letter. In sample 8 for 'D', variations has been observed in style of writing, appearance and in the formation letter except for the initial stroke.

In sample 9 and 11 for ' $d$ ', complete variation has been depicted in style of writing, appearance and in formation of letter. In sample 10 for ' $d$ ', slight variation in appearance and formation of letter but similarity was present in initial stroke. In sample 12 for 'd' variation in the formation of middle and terminal strokes has given letter a distinctive appearance and style though initial stroke of letter remains the same. In sample 13, 16 and 20 for ' $\mathrm{f}$ ', complete variation has been found in style of writing, appearance and formation of letter. In sample 14, 15, 17, 18 and 19 for ' $\mathrm{f}$ ' variation has been observed in formation of middle and terminal stroke as well as in appearance, although similarity has been found in initial stroke of letter. In sample 12 for ' $G$ ', variations have been depicted in formation of middle, terminal stroke of letter and in appearance of letter whereas similarity in initial stroke of the letter. In sample 22 for ' $g$ ', variation has been observed in overall appearance of letter but similarity in formation of letter.

In sample 23 for ' $g$ ', variation has been found in appearance and formation of letter. In sample 24 for ' $\mathrm{H}$ ', a complete variation has been noted in style of writing, appearance and in the formation of letter. In sample 25 and 26 for ' $h$ ', variation has been observed in upper loop of letter, giving it a different appearance whereas initial and terminal stroke has shown similarity. In sample 27, 28, 29 and 30 for 'I', variations has been depicted in style of writing, overall appearance, formation of letter, but the height of the main stem of the letter remained similar in all except for sample 30. In sample 31, 32, 34, 35 and 36 for ' $i$ ', variations has been observed in dotting of 'I' whereas, similarities has been observed in appearance and letter formation of the main body of the letter. In sample 33 for ' $I$ ', variation has been depicted in style of writing, appearance and in formation of letter. In sample 37 for ' $k$ ', variations were obtained in style of writing, appearance of letter and in the formation of letter. In sample 38 and 39 for ' 1 ', complete variation and modification has been noted in style of writing, appearance and in the formation of 
letter. In sample 40 and 41 for ' $M$ ' and ' $m$ ' respectively, has shown variations in style of writing, appearance, and in the formation of letter. In sample 42 for ' 0 ', variations have been observed in the style of writing, overall appearance and in the formation of letter. In sample 43 for 'p', variations were found in appearance and in formation of initial stroke whereas, similarity has been found in terminal stroke of the letter. In sample 44 for ' $p$ ', variations have been noted in appearance and in formation of terminal strokes whereas similarity in initial stroke of the letter. In sample 45 for 'q', variations have been depicted in style of writing, overall appearance and in formation of letter. In sample 46, 48 and 49 for ' $r$ ', by taking in account of various styles adopted by sample individual in producing a single letter in past handwriting, variations have been observed in style of writing, overall appearance and formation of letter. In sample 47 and 50 for ' $r$ ', variations have been noticed in appearance of letter and in formation of terminal stroke of letter whereas similarity in initial stroke of the letter. In sample 51 and 52 for ' $S$ ' and in sample 53 and 54 for ' $\mathrm{s}$ ', a distinctive variation have been observed in style of writing, overall appearance and in formation of letter. In sample 55 and 56 for ' $\mathrm{T}$ ', variations have been observed in style of writing, overall appearance and in letter formation. In sample 57 and 59 for ' $t$ ', a distinctive variation has been found in style of writing, overall appearance and in letter formation.

In sample 58 for ' $t$ ', variations are noticed in appearance and formation of letter whereas similarity in cutting of ' $t$ '. In sample 60 for ' $W$ ' as well as in sample 61 and 62 for ' $w$ ', there is a distinctive variation in style of writing, overall appearance and $\mathrm{n}$ formation of letter. In sample 63 and 64 for ' $x$ ', distinctive variations have been noticed in style of writing, appearance and in letter formation. In sample 65 to 69 for ' $y$ ', variations have been found in appearance of letter and in formation of terminal stroke whereas, similarity observed in initial stroke of the letter.

In Table 2 the letters showing variations in them along with their number has been shown. The letters that have depicted maximum variations in them with associating the concept of master pattern with them were ' $\mathbf{f}$ ' which is $\mathbf{2 4}$ in number, ' $\mathbf{i}$ ', ' $\mathbf{r}$ ' and ' $\mathbf{y}$ ' which are $\mathbf{1 5}$ in numbers for each. The letter including both capital and small which were cling to 
consistency with no marked variations in them are $\mathrm{C}, \mathrm{c}, \mathrm{E}, \mathrm{e}, \mathrm{F}, \mathrm{J}, \mathrm{j}, \mathrm{K}, \mathrm{L}$, $\mathrm{N}, \mathrm{n}, \mathrm{O}, \mathrm{P}, \mathrm{Q}, \mathrm{R}, \mathrm{U}, \mathrm{u}, \mathrm{V}, \mathrm{v}, \mathrm{X}, \mathrm{Y}, \mathrm{Z}$ and $\mathrm{z}$.

Table 1. Showing the number and percentage of letters in both capital and small letters consisting variations. $(n=540)$

\begin{tabular}{|c|c|c|c|c|}
\hline \multirow{2}{*}{ S. No. } & \multirow{2}{*}{ Letter } & \multicolumn{3}{|c|}{$\begin{array}{l}\text { Variation found in Letter formation } \\
\text { in Handwritting samples }\end{array}$} \\
\hline & & Past & Present-I & Present-II \\
\hline 1 & A & & & \\
\hline 2 & A & & & \\
\hline 3 & $\mathrm{a}$ & & & \\
\hline 4 & B & & & \\
\hline 5 & $\mathrm{~b}$ & & & \\
\hline 6 & $b$ & & & \\
\hline 7 & b & & & \\
\hline
\end{tabular}




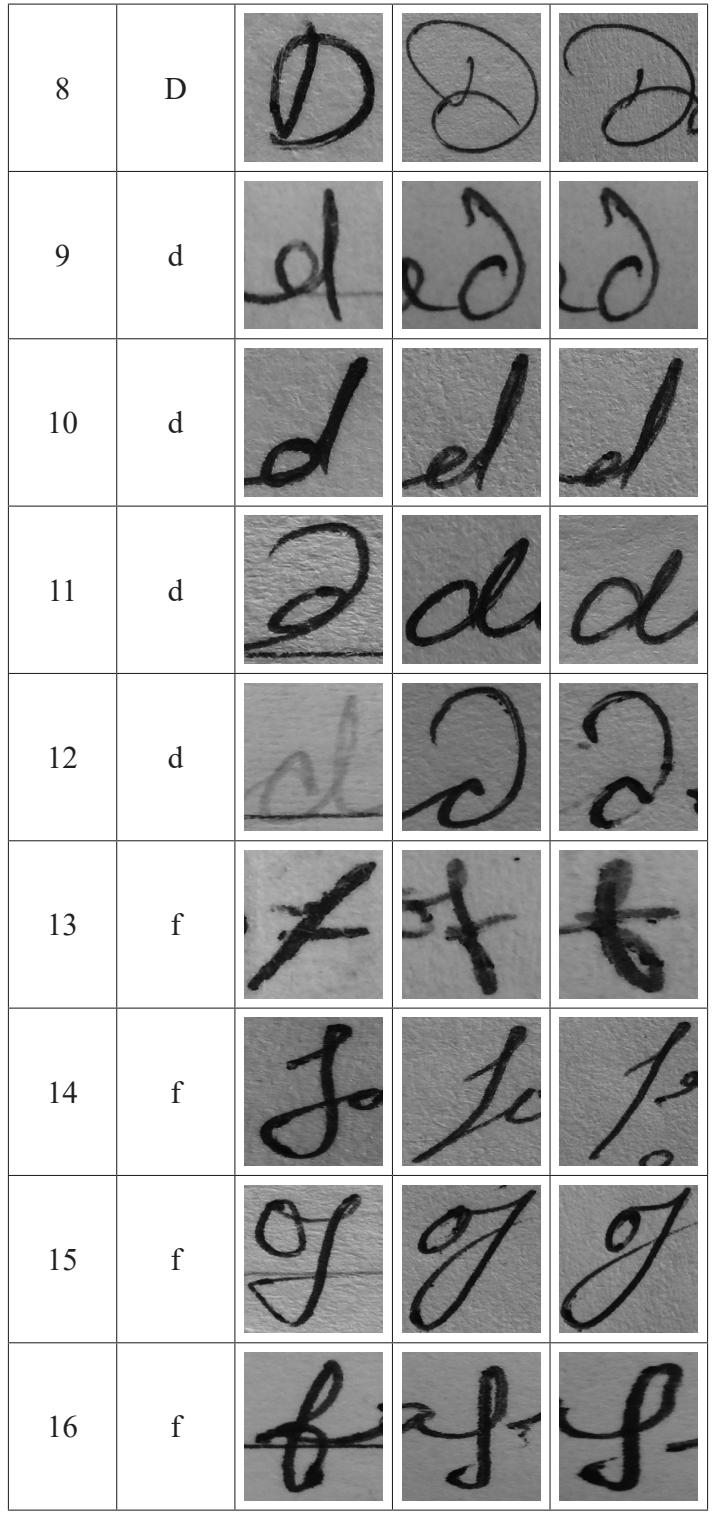




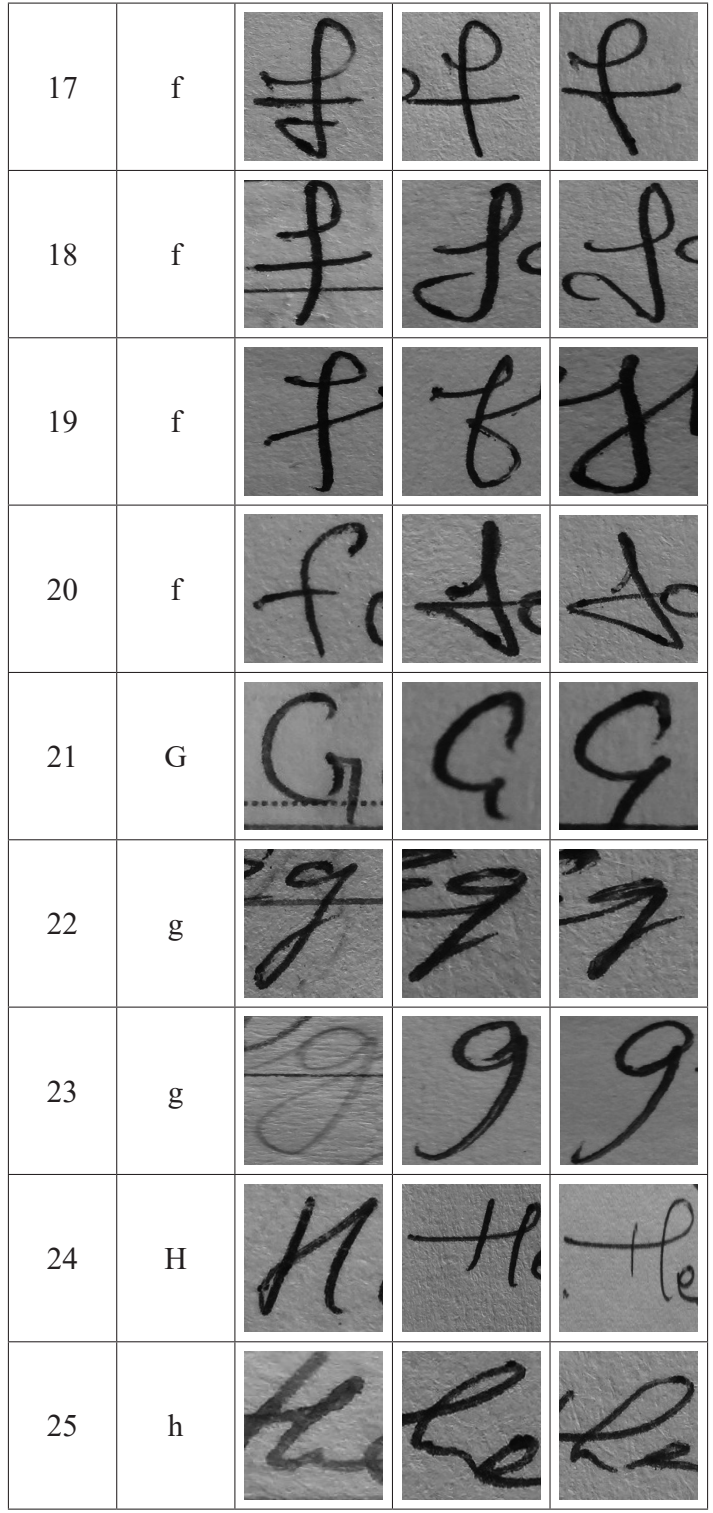




\begin{tabular}{|l|l|l|l|l|}
\hline 26 & $\mathrm{~h}$ & & & \\
\hline
\end{tabular}




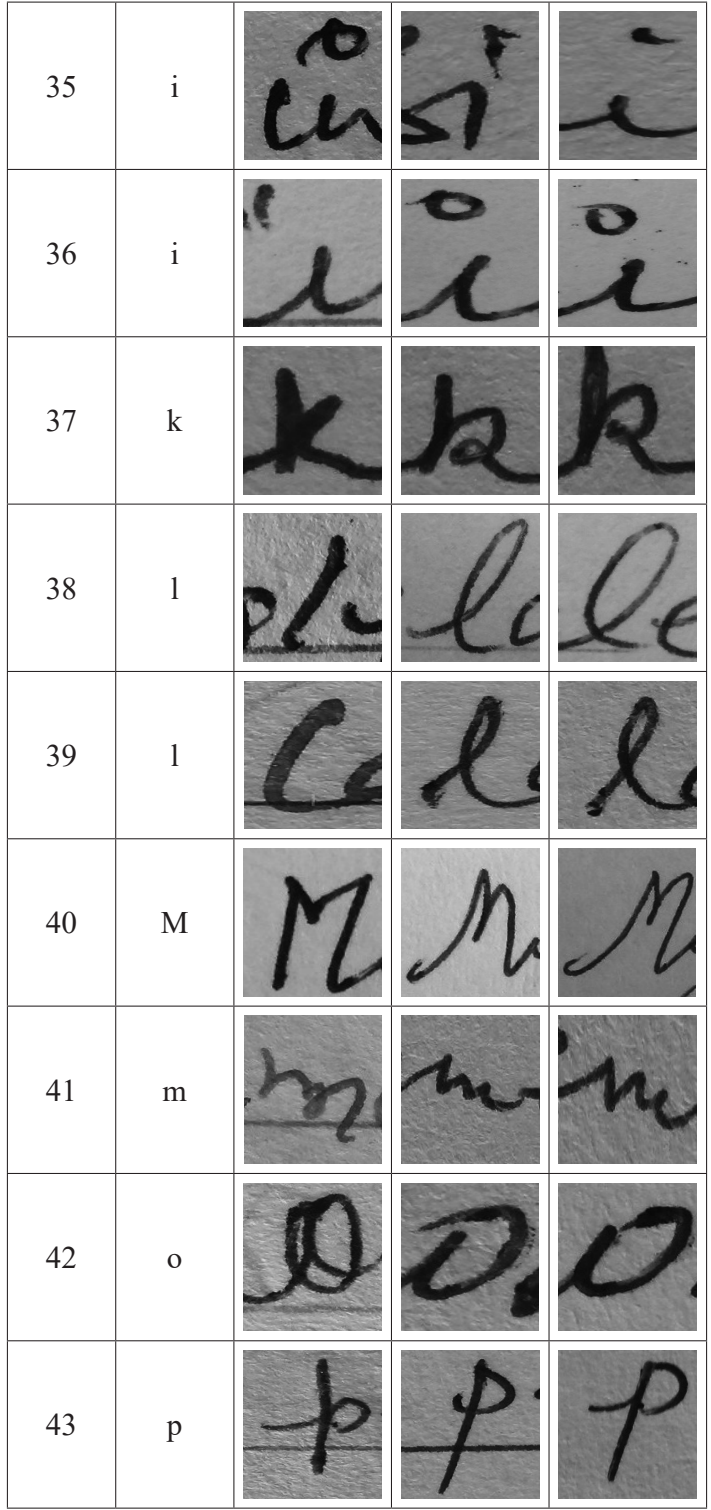

Nowa Kodyfikacja Prawa Karnego 44, 2017

(C) for this edition by CNS 


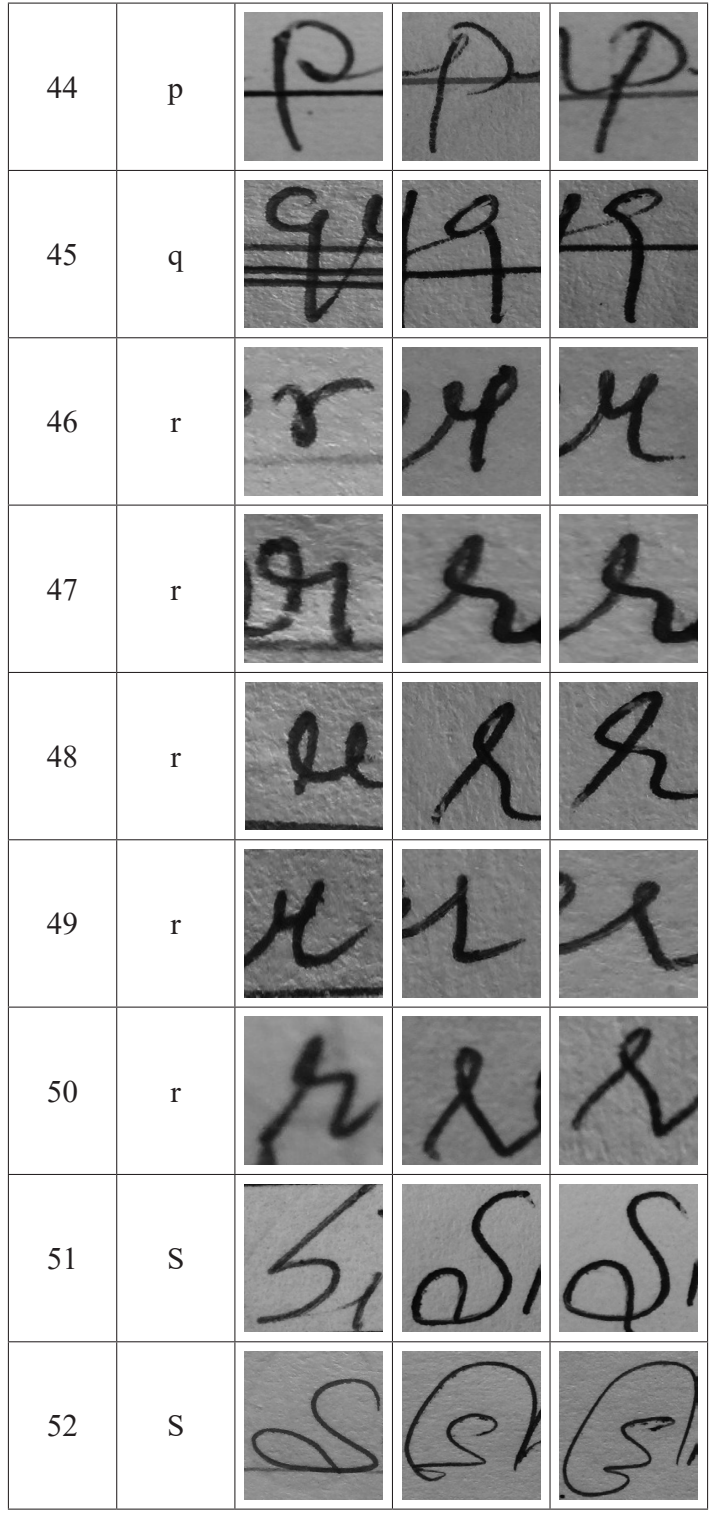




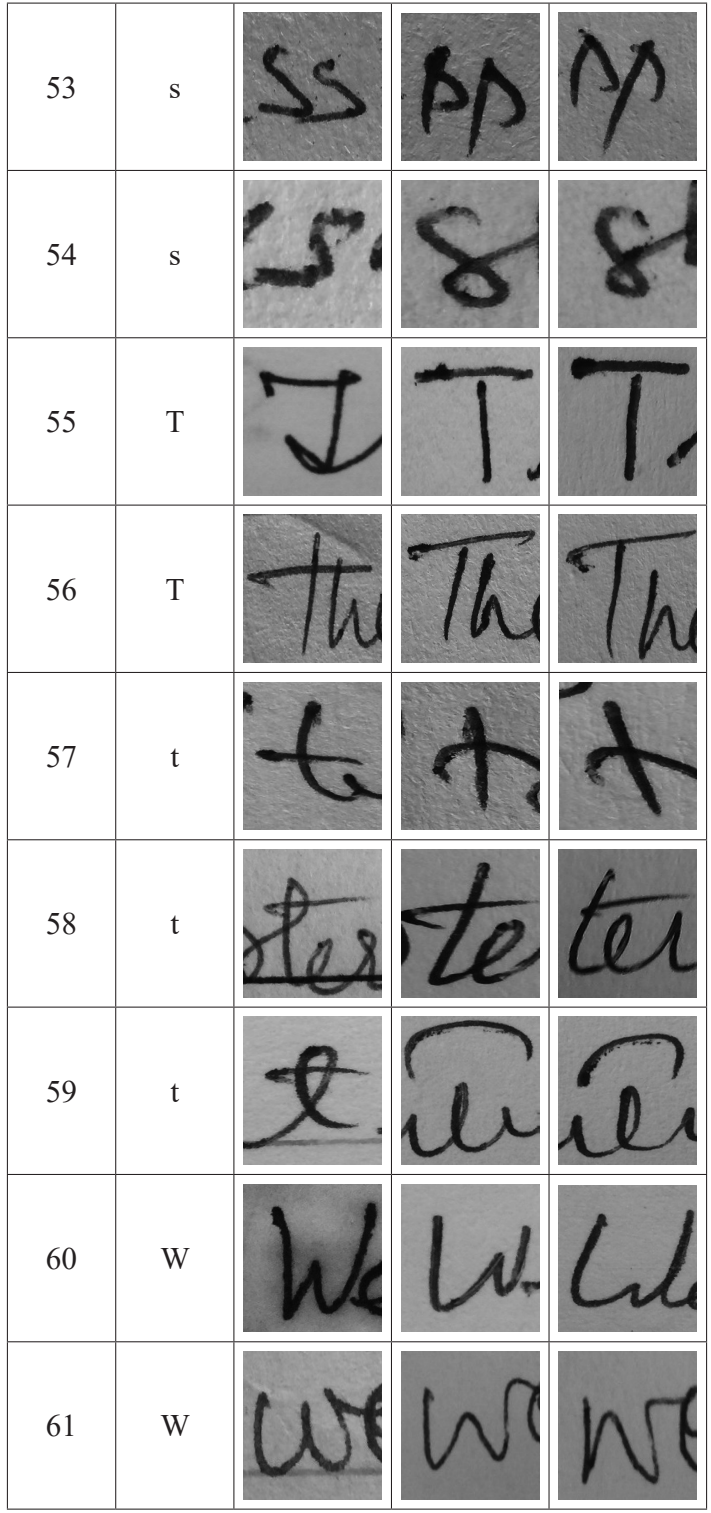

Nowa Kodyfikacja Prawa Karnego 44, 2017

(C) for this edition by CNS 


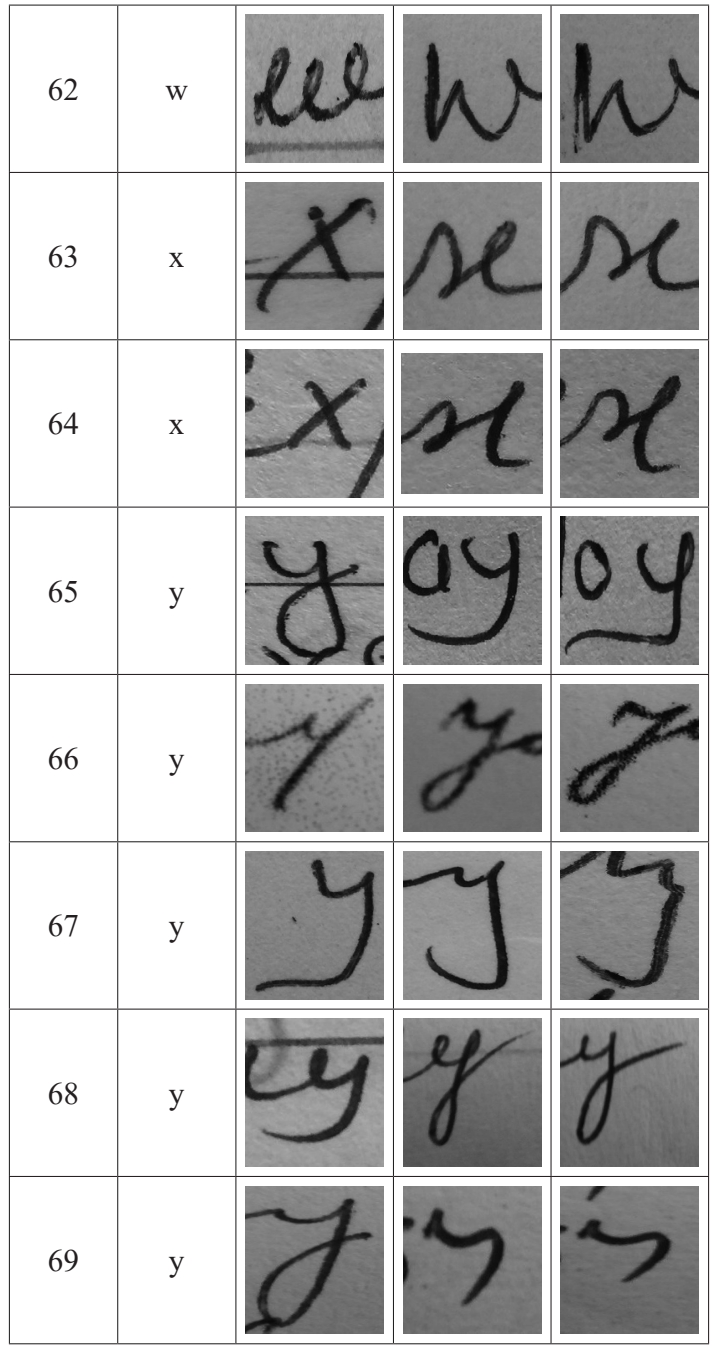




\begin{tabular}{|c|c|}
\hline Letters & No. of samples depicting variations (\%) \\
\hline A & $6(1.11 \%)$ \\
\hline $\mathrm{a}$ & $3(0.56 \%)$ \\
\hline B & $3(0.56 \%)$ \\
\hline $\mathrm{b}$ & $9(1.67 \%)$ \\
\hline $\mathrm{D}$ & $3(0.56 \%)$ \\
\hline d & $12(2.2 \%)$ \\
\hline f & $24(4.4 \%)$ \\
\hline G & $3(0.56 \%)$ \\
\hline g & $6(1.1 \%)$ \\
\hline $\mathrm{H}$ & $3(0.56 \%)$ \\
\hline $\mathrm{h}$ & $6(1.11 \%)$ \\
\hline I & $12(2.2 \%)$ \\
\hline $\mathbf{i}$ & $15(2.8 \%)$ \\
\hline $\mathrm{k}$ & $3(0.56 \%)$ \\
\hline 1 & $6(1.11 \%)$ \\
\hline M & $3(0.56 \%)$ \\
\hline $\mathrm{m}$ & $3(0.56 \%)$ \\
\hline o & $3(0.56 \%)$ \\
\hline $\mathrm{p}$ & $6(1.11 \%)$ \\
\hline q & $3(0.56 \%)$ \\
\hline $\mathrm{r}$ & $15(2.8 \%)$ \\
\hline $\mathrm{S}$ & $6(1.11 \%)$ \\
\hline $\mathrm{s}$ & $6(1.11 \%)$ \\
\hline $\mathrm{T}$ & $6(1.11 \%)$ \\
\hline $\mathrm{t}$ & $6(1.11 \%)$ \\
\hline W & $3(0.56 \%)$ \\
\hline $\mathrm{w}$ & $6(1.11 \%)$ \\
\hline $\mathrm{x}$ & $6(1.11 \%)$ \\
\hline $\mathbf{y}$ & $15(2.8 \%)$ \\
\hline $\begin{array}{c}\text { Total variations in letter } \\
\text { formation }\end{array}$ & $201(37.2 \%)$ \\
\hline
\end{tabular}




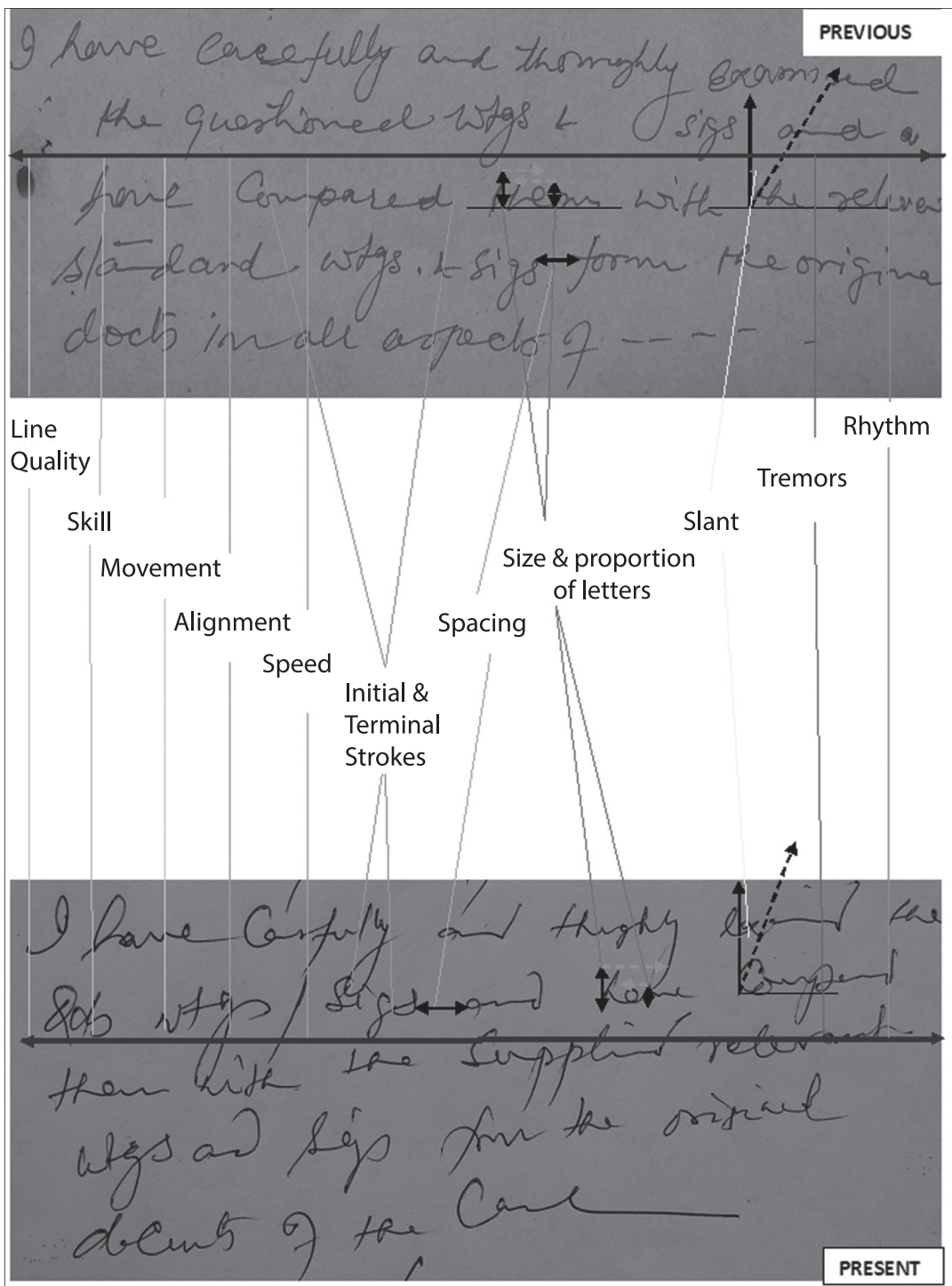

Figure 1. Showing comparative analysis of class characteristics in previous and present handwriting sample (time gap of 38 years) of an individual 


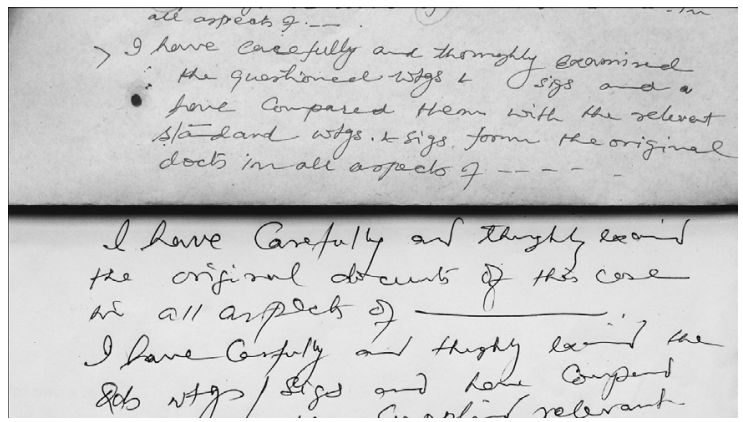

Figure 2. Comparison of standard handwriting (time gap of 38 years) with the handwriting of 3 years of time gap of an individual

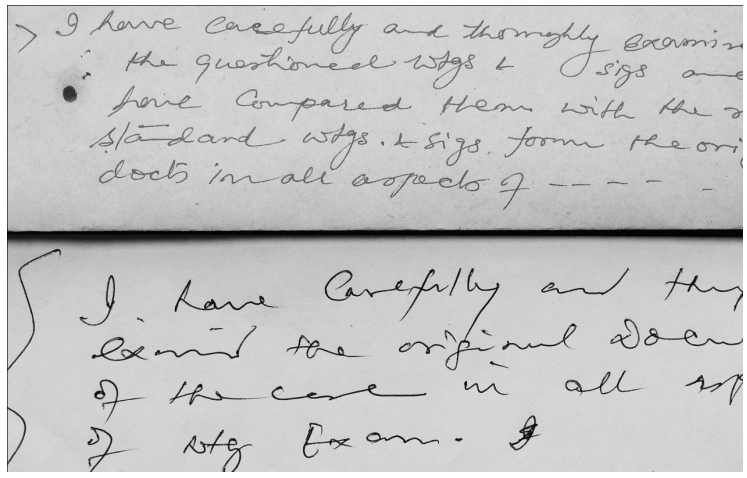

Figure 3. Comparison of standard handwriting (time gap of 38 years) with the handwriting of 7 years of time gap of an individual

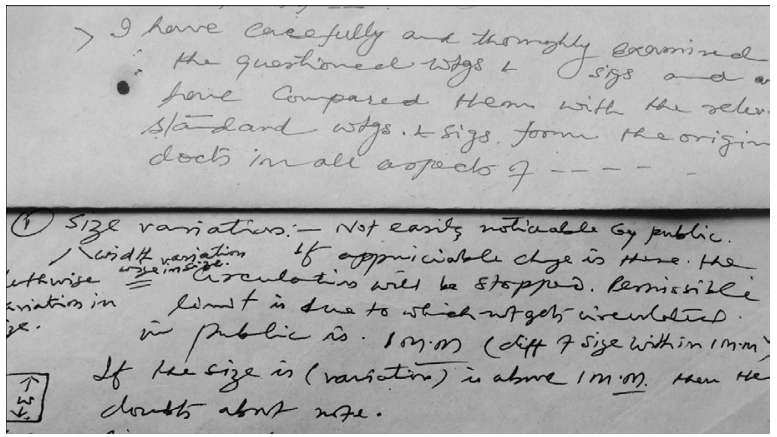

Figure 4. Comparison of standard handwriting (time gap of 38 years) with the handwriting of 17 years of time gap of an individual 


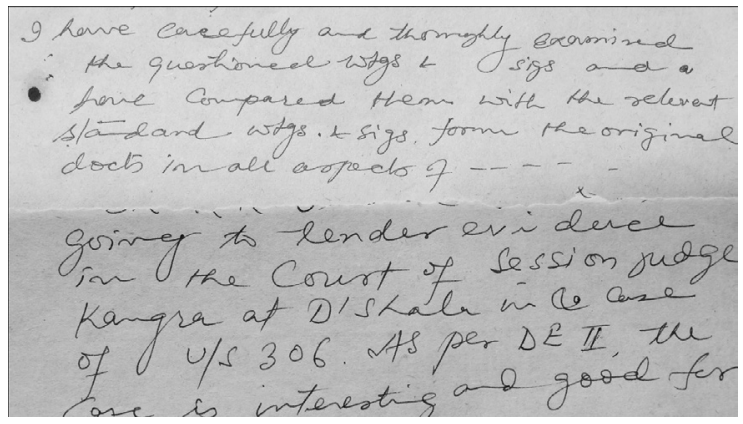

Figure 5. Comparison of standard handwriting (time gap of 38 years) with the handwriting of 22 years of time gap of an individual

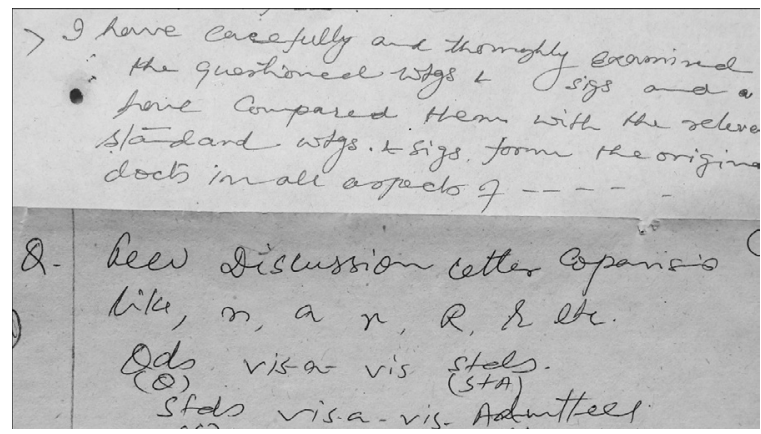

Figure 6. Comparison of standard handwriting (time gap of 38 years) with the handwriting of 29 years of time gap of an individual

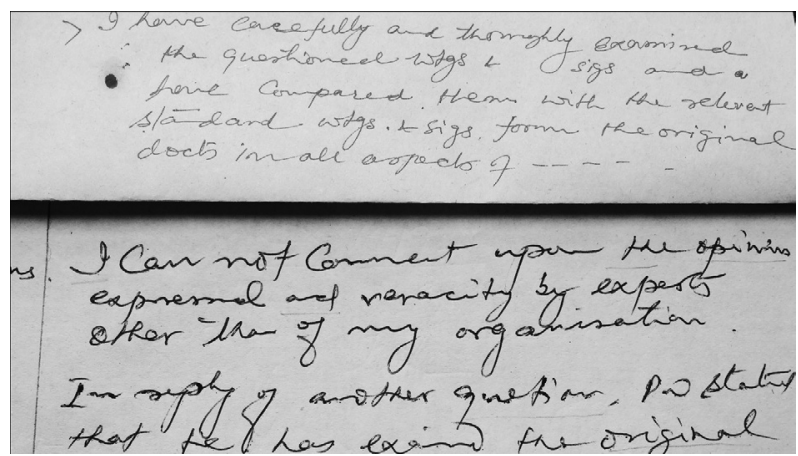

Figure 7. Comparison of standard handwriting (time gap of 38 years) with the handwriting of 32 years of time gap of an individual 


\section{Discussion}

The range of writing can also be named as the master pattern of the writer, includes all the characteristics, patterns, and idiosyncrasies that a writer uses when engaged in the act of writing. Hardless (1995) stated that the position of the dots, crossing-strokes and placing of punctuation marks are highly characteristic in any handwriting. Every person places these marks according to his or her own individual habits and style. For instance, the comma may be either big or small; the position of the dots may be exactly over the stems of ' $i$ ' or they may be placed towards the left or right. Similarly, the crossings of ' $t$ ' may be to the left of the stem or to the right, without touching the stem or it may cross the stem or main body. According to Kelly and Lindblom (2006) many individuals have modified this element of their writing to suit their personal tastes. Some writers have the tendency to start the initial strokes of their letters well below the baseline, while others can commence them above the recommended starting position. There are few writers who use long and short initial strokes, depending on the particular character and its position in a word. Like initial strokes, terminal strokes are also prescribed by copybook forms. Individuals acquire a personal style of writing invariably deviate from letterforms dictated by the copybook and they usually add curled strokes, extensions, or embellishments to the ends of certain letters. These writing features are quite consistent and, therefore, warrant consideration when comparing two groups of writing.

The examination of variations in letter formation with time period of 2 years to 33 years obtained in Past and Present handwritings from the same individuals is a new area of research in the field of questioned documents. The maximum variations has been observed in ' $\mathbf{f}$ ', ' $\mathbf{y}$ ', ' $\mathbf{r}$ ' and 'i', then rest of the letters that have shown variations in their style of writing, appearance and letter formation. Matuszewski (2004) studied the extent of natural and intra-individual variations in selected constructional characteristics in women's signature and gathered from in which 5 were signed at once, at weekly interval or longer, for a duration of 15 weeks. Though he studied the variations in signatures in letters - a, s, w and k; due to this reason the results cannot be compared with the present research. In the present investigation all letters $(\mathrm{a}-\mathrm{z})$ were selected and on comparison 
with these letters, 'a', 's', 'w' and ' $k$ ' have shown minor variations in them. Apart from this there is no significant and relevant research to be compared with the present research and not much can be said. Due to non-availability of data on this research it is expected to put forward new grounds to differentiate between genuine handwriting with the forged or disguised ones.

\section{Conclusion}

It can be concluded from the present investigation that apart from intrinsic and extrinsic factors in handwriting examination, age and time gap played more significant role in inducing natural variations. In present scenario on commencing with case, contemporary writings are foremost requisite and on unavailability of them this research work will provide useful information as being a new mode of investigation and will surely aid document experts to undertake these cases and to reach out a correct opinion. With the due effect of the findings gathered from the present investigation the cases lacking in contemporary handwritings can be undertaken with ease by taking into account the letters - ' $\mathrm{f}, \mathrm{y}, \mathrm{r}$ and $\mathrm{i}$ ' which have a major effect of natural variations on them which in turn makes them unreliable and should be avoided in the process of comparison as well as while forming an opinion.

\section{Acknowledgements}

The senior author (Dr Shruti Gupta) is highly thankful to UGC for the award of Senior Research Fellowship and providing the financial assistance to carry out the research work. We are thankful to all sources and persons who have contributed in carrying out this research work and in the collection of samples for the present study.

\section{References}

Kelly, J.S., Lindblom, B.S. (2006): Science, Handwriting Examination and the Courts. Scientific Examinations of Questioned Documents, $2^{\text {nd }}$ ed., CRC Press, Taylor \& Francis group. 
Gupta, S., Garg, K.R., Nath, S. (2012): “The influence of Natural variations on handwriting characteristics from different age groups with time gap". Turkish Journal of Forensic Science, 11 (3), pp. 11-20.

Gupta, S.C. and Kapoor, V.K. (1996): Fundamental of Applied Sciences, $3^{\text {rd }}$ ed. - reprint, Sultan Chand \& Sons, India, pp. 36-48.

Gupta, S.P. (2011): Statistical Methods, $4^{\text {th }}$ edition, Sultan Chand \& Sons, India, pp. $110-160$. Hardless, H.R. (1995): Disputed Documents Examination and Finger-Prints Identification, 5th edition, Law Book Company, India, pp. 21-44.

Harrison, W.R. (2008): Suspected Documents and their Scientific Examination, $4^{\text {th }}$ Indian reprint, Universal Law Publishing Co. Pvt. Ltd., pp. 288-420.

Hilton, O. (1984): Scientific Examination of Questioned Documents, Elsevier Science Publishing Co. lnc., New York, pp. 56-67.

Huber, A.R. and Headrick, A.M. (1999): Handwriting Identification Facts and Fundamentals, CRC Press, Boca Raton London, pp. 73-141.

Matuszewski, S. (2004): "Natural Variation in selected constructional features of Female Signatures”, Problems in Forensic Science, 57, pp. 24-43.

McCabe, A., Trevathan, J. and Read, W. (2008): "Neural Network - Based Handwritten signature verification”, Journal of Computers, 3 (8), pp. 9-22.

Sarangi, P.K., Sahoo, A.K. and Ahmed, P. (2012): "Recognition of Isolated Handwritten Oriya numerals using Hopfied Neural Network”, International Journal of Computer Application, 40 (8), pp. 36-42.

\section{Summary}

Handwriting is made up of countless habitual patterns. An individual's handwriting is made up of a complexity of habitual patterns that are repeated within a typical range of variation around the model patterns. The muscle coordination of these and perceptions of how an individual sense form helps each one to develop one's own Master Pattern of writing. A total number of 540 (60 samples from each age group - 30 samples each from males \& females), has been collected from 9 different age groups. Three handwriting samples - two in present handwriting (with a gap of 5-10 minutes between the two handwritings) and one old or past handwriting sample collected from each individual (gap ranged from 2-33 years between present and old handwritings). With the due effect of the findings gathered from the present investigation the cases lacking in contemporary handwritings can be undertaken with ease by taking into account the letters — ' $f, y, r$ and i' which have a major effect of natural variations on them which in turn makes them unreliable and should be avoided in the process of comparison as well as while forming an opinion.

Keywords: natural variations, master pattern, contemporary, unreliable. 